MS. KATHRINE PAPE (Orcid ID : 0000-0003-2925-9668)

DR. CAROLINE LODGE (Orcid ID : 0000-0002-2342-3888)

DR. ADRIAN LOWE (Orcid ID : 0000-0002-4691-8162)

1

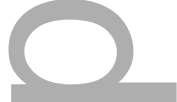

묘

Article type : Letter to the Editor

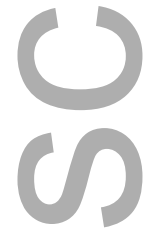

Is self-reported history of eczema and hay-fever a valid measure of atopy in those who report current asthma?

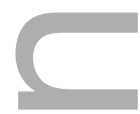

Kathrine Pape, $\mathrm{MSc}^{1,2}$; Vivi Schlünssen MD, $\mathrm{PhD}^{1,2}$; Caroline Jane Lodge, $\mathrm{PhD}^{3}$; Jennifer $\mathrm{L}$ Perret, PhD ${ }^{3,4}$; E. Haydn Walters $\mathrm{DM}^{3}$; Dinh Bui., PhD³; Bircan Erbas, PhD³ Cecilie Svanes, MD, PhD ${ }^{5,6}$; Garun S. Hamilton MBBS, PhD ${ }^{7,8}$; Paul S. Thomas, MD ${ }^{9}$; Karin S. Hougaard, PhD ${ }^{1,10}$; Michael J. Abramson PhD ${ }^{11}$; Shyamali C. Dharmage, MD, PhD ${ }^{3 *}$; Adrian J. Lowe $\mathrm{PhD}^{3 *}$.

*Equal senior author.

${ }^{1}$ National Research Center for the Working Environment, - Copenhagen (Denmark)

2 Institute of Environmental and Occupational Medicine, Department of Public Health, Aarhus University, - Aarhus (Denmark)

3 Allergy and Lung Health Unit, Melbourne School of Population and Global Health, University of Melbourne - Melbourne (Australia)

${ }^{4}$ Department of Respiratory and Sleep Medicine, Austin Hospital - Melbourne (Australia)

This is the author manuscript accepted for publication and has undergone full peer review but has not been through the copyediting, typesetting, pagination and proofreading process, which may lead to differences between this version and the Version of Record. Please cite this article as doi: $10.1111 /$ ALL.14440

This article is protected by copyright. All rights reserved 
${ }^{5}$ Centre for International Health, Department of Global Public Health and Primary Care, University of Bergen - Bergen (Norway)

${ }^{6}$ Department of Occupational Medicine, Haukeland Hospital - Bergen (Norway)

${ }^{7}$ School of Clinical Sciences, Monash University, Melbourne, Australia

${ }^{8}$ Monash Lung and Sleep, Monash Health, Melbourne Australia

${ }^{9}$ Prince of Wales' Clinical School, UNSW and Respiratory Medicine, Prince of Wales' Hospital Randwick, NSW Australia.

${ }^{10}$ Department of Public Health, University of Copenhagen - Copenhagen (Denmark)

11 School of Public Health \& Preventive Medicine, Monash University - Melbourne (Australia)

Corresponding author: Professor Shyamali Dharmage, Allergy and Lung Health Unit, Melbourne School of Population and Global Health, Level 3, 207 Bouverie Street,

The University of Melbourne, Victoria 3010 E-mail: s.dharmage@unimelb.edu.au

\section{Conflicts of Interest}

JLP has received a travel grant from Boehringer-Ingelheim, KPM have received travel grants from Oticon and Knud Højgaards Fond, MJA holds investigator initiated grants from Pfizer and Boehringer-Ingelheim for unrelated research. He has undertaken an unrelated consultancy for Sanofi and has received a speaker fee from GSK. The remaining authors have no conflicts of interest to declare.

\section{Funding sources}

Kathrine Pape received a PhD scholarship from Aarhus University and the Danish Working Environment Research Fund, Denmark (Grant no. 17-2015-09 / 20150067134). S.C.D, A.J.L, J.L.P., and C.J.L are supported by the National Health and Medical Research Council (NHMRC) of Australia. Both MACS and TAHS cohorts are supported by grants from the NHMRC (MACS grant \# APP454856; TAHS grants \#299901, \#454425, \#566931 \#628513 and \#1021275). The first 6 years of MACS was funded by Nestec, a subsiduary of Nestlé Australia. The authors have an equipment grant from the University of Melbourne (Melbourne, Australia).

This article is protected by copyright. All rights reserved 


\section{SUMMARY}

This study suggests that in the absence of skin prick test (SPT) or slgE data, self-reported hayfever "and/or" eczema provides a useful definition of allergic asthma for epidemiological studies.

\section{KEY WORDS}

ALLERGIC ASTHMA, ALLERGY, HAYFEVER, ECZEMA, SKIN PRICK TEST, VALIDITY

\section{ABBREVIATIONS}

$\mathrm{Cl}=$ confidence interval

DOR = Diagnostic Odds Ratio

L95 = Lower $95 \%$ Confidence Interval

MACS = Melbourne Atopy Cohort Study

NLR = Negative Likelihood Ratio

PLR = Positive Likelihood Ratio

SPT $=$ Skin Prick Test

slgE = Specific Immunoglobulin E

TAHS = Tasmanian Longitudinal Health STUDY

U95 = Upper $95 \%$ Confidence Interval

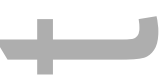

To the Editor: There is growing awareness that "asthma" is a clinical syndrome with multiple distinct pathophysiological mechanisms, or endotypes, leading to variable clinical expression of disease. Distinction of asthma as a clinical syndrome is of increasing importance since the emergence of targeted biological therapies (1). Asthma is most often phenotyped as allergic or non-allergic, based on evidence of sensitisation to specific allergens measured as skin prick tests (SPT) or in vitro immunoglobulin E (slgE) (2). However, in large scale epidemiological studies, measurement of slgE or SPT is often not feasible due to cost or 
logistical constraints. Allergic asthma has often been classified as asthma with concurrent self-reported hayfever and/or eczema $(3,4)$. Similarly, SPT or sIgE are uncommonly measured in primary care settings, with assessment of "atopy" in those with asthma typically based on reports of other allergic conditions. It is not clear how valid this approach is or how frequently participants are misclassified. We have examined the validity of using self-reported hayfever and/or eczema to define allergic status among asthmatics compared to SPT as a "gold standard".

This analysis used data from two independent studies: The Melbourne Atopy Cohort Study (MACS) (5) and The Tasmanian Longitudinal Health Study (TAHS) (6). MACS is a birth-cohort of children, with family history of allergic diseases, born between 1990 and 1994. Parents and siblings were included in later follow-ups. TAHS is a cohort of children born in Tasmania in 1961, plus their families. Parents and siblings have been studied in later phases. Participants from MACS' 18 year follow-up, together with TAHS probands from the 2012 and TAHS siblings from the 2007 study were included if they fulfilled these criteria: (i) current asthma, (ii) valid skin prick tests, and (iii) complete information on hayfever and eczema ever (supplementary Figure S1).

Current asthma was defined by self-reported doctor diagnosed asthma and self-reported concurrent episodes of asthma, wheezing breathing or any asthma medication use within the last 12 months. Hayfever ever was based on self-reported episodes of ever hayfever in MACS and slightly more broadly defined in TAHS by also including nasal allergies. Eczema ever was based on participant reports of ever eczema in MACS and slightly more broadly defined in TAHS by also including any kind of skin allergy.

A positive skin prick test was defined as a mean wheal diameter of at least $3 \mathrm{~mm}$ greater than the saline control for one or more of the following allergen extracts: dust mite $(D$. pteronyssinus), cat, Alternaria, Penicillium, mixed grasses or rye grass pollen. Results were deemed invalid if the histamine control reaction was below $3 \mathrm{~mm}$ and no other reaction above $3 \mathrm{~mm}$, to any allergen wheals, was identified (7). The period prevalence (in the past 12 months) of reported asthma symptoms was assessed, when the skin prick tests were performed. 
Sensitivity, specificity, positive likelihood ratio (PLR), negative likelihood ratio (NLR) and diagnostic odds ratios (DOR) were calculated with 95\% confidence intervals (CI). Probands, siblings and parents were initially analysed separately, then probands, siblings and parents were pooled in each study. Asthma defined to be allergic or non-allergic was assessed for each individual. Clustering by family was adjusted within each study using the PROC GENMOD procedure in SAS (SAS Institute Inc., Cary, NC, USA) version 9.4. Due to high heterogeneity between MACS and TAHS, as assessed by using $\mathrm{I}^{2}$, pooled estimates are not shown. Of 937 participants with current asthma, 78\% had a positive SPT and 89\% ever had hayfever and/or eczema (Table I).

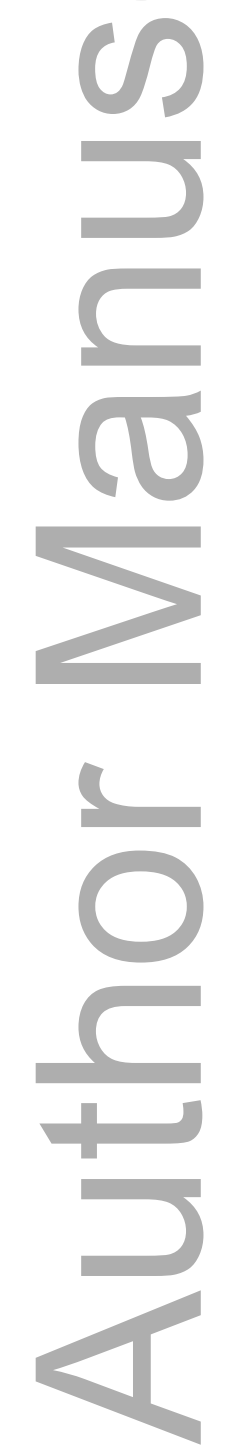

This article is protected by copyright. All rights reserved 
Table I Descriptive data of the study population with current asthma in the MACS 18 years follow up and TAHS 2012 and 2007 follow up

\begin{tabular}{|c|c|c|c|c|c|c|c|c|}
\hline \multirow{3}{*}{ ك- } & \multicolumn{4}{|c|}{ MACS } & \multicolumn{3}{|c|}{ TAHS } & \multirow[t]{2}{*}{ TOTAL } \\
\hline & & 18 year & follow up & & 2012 follow up & 2007 follow up & & \\
\hline & Probands, $n=89$ & Siblings, $n=111$ & Parents, $n=156$ & Total, $n=356$ & Probands, $n=225$ & Siblings, $n=356$ & Total, $n=581$ & $n=937$ \\
\hline Female & $47.2 \%(42 / 89)$ & $50.5 \%(56 / 111)$ & $69.9 \%(109 / 156)$ & $58.2 \%(207 / 356)$ & $55.6 \%(125 / 225)$ & $53.0 \%(188 / 355)$ & $54.0 \%(313 / 580)$ & $55.6 \%(520 / 936)$ \\
\hline Mean age in years (SD) & $18.2(1.4)$ & $20.4(6.2)$ & $50.9(4.4)$ & $33.2(16.3)$ & $52.1(0.9)$ & $49.4(5.7)$ & $50.5(4.7)$ & $41.9(11.5)$ \\
\hline Positive skin prick test & $87.6 \%(78 / 89)$ & $85.6 \%(95 / 111)$ & $86.5 \%(135 / 156)$ & $86.5 \%(308 / 356)$ & $73.8 \%(166 / 225)$ & $71.6 \%(255 / 356)$ & $72.5 \%(421 / 581)$ & $77.8 \%(729 / 937)$ \\
\hline Ever hayfeve & $73.0 \%(65 / 89)$ & $70.3 \%(78 / 111)$ & $85.3 \%(133 / 156)$ & $77.5 \%(276 / 356)$ & $83.1 \%(187 / 225)$ & $77.8 \%(277 / 356)$ & $79.9 \%(464 / 581)$ & $79.0 \%(740 / 937)$ \\
\hline Ever ecze & $56.2 \%(50 / 89)$ & $68.5 \%(76 / 111)$ & $44.9 \%(70 / 156)$ & $55.1 \%(196 / 356)$ & $61.8 \%(139 / 225)$ & $53.1 \%(189 / 356)$ & $56.5 \%(328 / 581)$ & $55.9 \%(524 / 937)$ \\
\hline Ever hayfever and eczema & $43.8 \%(39 / 89)$ & $50.5 \%(56 / 111)$ & $42.3 \%(66 / 156)$ & $45.2 \%(161 / 356)$ & $52.9 \%(119 / 225)$ & $43.0 \%(153 / 356)$ & $46.8 \%(272 / 581)$ & $46.2 \%(433 / 937)$ \\
\hline Ever hayfever and/or eczema & $85.4 \%(76 / 89)$ & $88.3 \%(98 / 111)$ & $87.8 \%(137 / 156)$ & $87.4 \%(311 / 356)$ & $92.0 \%(207 / 225)$ & $87.9 \%(313 / 356)$ & $89.5 \%(520 / 581)$ & $88.7 \%(831 / 937)$ \\
\hline
\end{tabular}

$n=$ number of participants, SD = Standard deviation, MACS = Melbourne Atopy Cohort Study, TAHS = Tasmanian Longitudinal Health STUDY

This article is protected by copyright. All rights reserved 
1 Figure I: Sensitivity, specificity and diagnostic odds ratio of hayfever, eczema and combination of these

3

4

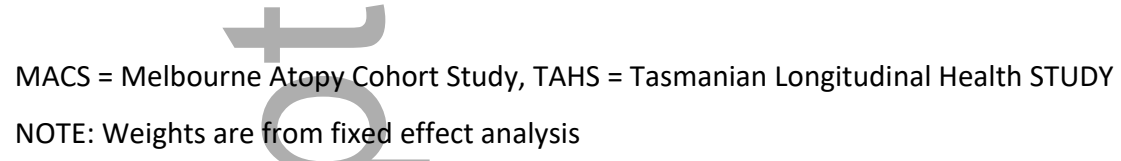

Supplementary Figure S1: Flowchart - The Melbourne Atopy Cohort Study (MACS) and The Tasmanian Longitudinal Health Study (TAHS) participants

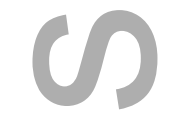

MACS and TAHS estimates of self-reported hayfever ever compared with SPT-defined allergic asthma showed relatively high sensitivity $\geq 0.82$, but moderate specificity $\geq 0.60$, and DOR $>4.13$, Figure I. The corresponding PLR was $\geq 1.57$ and NLR was $\leq 0.23$, see supplementary Table SI. The results varied between groups, and were higher in older participants (MACS parents and TAHS participants). Using self-reported ever eczema showed lower utility ( $D O R \geq 0.74$ ) as did combining hayfever and eczema ever (requiring both) (DOR $\geq 0.19$ ). In contrast, combining current asthma with hayfever "and/or" eczema estimates of sensitivity were at least 0.90 , specificity $\geq 0.69$, PLR $>2.92$, NLR of $<0.14$, and DOR $\geq 20.5$.

We found that combining self-reported hayfever and/or eczema ever, provided high sensitivity, specificity, PLR and a large DOR for defining atopic asthma, and a low NLR. Current asthma combined with hayfever ever alone showed an acceptable sensitivity, moderate specificity and less useful clinical PLR, NLR and DOR when compared with SPT-defined allergic asthma. Combining current asthma with eczema alone or hayfever and eczema showed much poorer results.

This is the first study to examine the validity of combining self-reported hayfever as well as eczema to identify atopic versus non-atopic asthma in young to middle-aged adults. A previous study of Swiss school children (8) examined the validity of self-reported hayfever ever compared with SPT and showed high specificity (useful in including allergy), but low sensitivity. Even though 
1 hayfever can present in childhood, it is more common in adults than children (9), which may explain the low sensitivity observed in the Swiss study.

It is a limitation that our study is based on an Australian population, as it has one of the highest rates of atopy in the world. Furthermore MACS is a high-risk birth cohort based on children with a family history of allergic diseases resulting in a population with even higher rates of allergy (5). While the rates of allergy would be higher in this study, it is unlikely that this would affect the validity of the symptoms combinations compared with definitions including SPTs. Our results are restricted to the specific allergen extracts measured in the skin prick tests, using the main allergens of Australia. We adopted SPT as gold standard, and it would be useful to also explore the use of in vitro slgE (2). We used self-reported doctor-diagnosed asthma and self-reported concurrent symptoms of asthma, which are used in most epidemiological studies. While selfreported asthma and clinical diagnosis of asthma showed relatively good agreement $(k=0.78)(10)$, it would be useful also to explore these associations using clinical assessed diagnosis of asthma. It should be noted that in most epidemiological studies, current asthma status is defined by patient report, rather than confirmed clinical diagnosis. The differences between the MACS and TAHS cohorts, including the definition of hayfever and eczema, age of the participants and nature of the cohorts (high risk versus population-based) may have led to highly heterogeneous findings. Hayfever and eczema were furthermore, more broadly defined in TAHS. This is a limitation as it prevented us from pooling of the results.

Our results suggest that a history of self-reported hayfever and/or eczema combined provides the most accurate means to define allergic asthma in epidemiological studies without direct assessment of SPT or slgE measurements.

\section{Ethics approval and consent to participate}

All participants provided written informed consent. The MACS project was approved by the Human Research Ethics Committee of the Mercy Hospital for Women (up to 12 years, reference numbers R07/20 and R88/06) and Royal Children's Hospital (18 years, reference number 28035). 
1 The TAHS was approved by Human Ethics Review Committees at The Universities of Melbourne 2 (approval number 040375), Tasmania (040375.1) and New South Wales (08094), the Alfred 3 (1118/04) and Royal Brisbane and Women's Hospital Health Service District (2006/037).

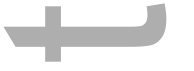

\section{Data Availability}

The data that support the findings of this study are available on request from the corresponding author. The data are not publicly available due to privacy or ethical restrictions.

\section{Authors' contributions}

KP, VS, KSH, SCD and AJL: Conception and design of the analysis, interpretation of data and drafting the work. SCD, AJL, CJL, BE, CS, PST, and MJA: Design of the 18 year follow-up of the MACS for funding proposals and data collection. SCD, JP, HW, DB, BE, CS, GSH, PST, and MJA: Design of the TAHS follow-up studies, writing grant proposals and data collection. All authors contributed to the manuscript drafts revising for important intellectual content and have read and approved the manuscript.

\section{Authors' contributions}

$\mathrm{KP}, \mathrm{VS}, \mathrm{KSH}, \mathrm{SCD}$ and $\mathrm{AJL}$ : Conception and design of the analysis, interpretation of data and drafting the work. SCD, AJL, CJL, BE, CS, PST, and MJA: Design of the 18 year follow-up of the MACS for funding proposals and data collection. SCD, JP, HW, DB, BE, CS, GSH, PST, and MJA: Design of the TAHS follow-up studies, writing grant proposals and data collection. All authors contributed to the manuscript drafts revising for important intellectual content and have read and approved the manuscript.

\section{Acknowledgments}

MACS: We thank Dr John Thorburn, FRACP, for assistance in patient recruitment and administrative assistance and the Mercy Maternity Hospital Department of Obstetrics for participant recruitment, and Dr David Hill and Cliff Hosking for study leadership up to the 12-year follow-up. We thank Anne Balloch for assistance with data management, Rida Asif, Carlie Dunford and Brittany Campbell for project coordination, and Jeeva Sanjeevan for clinical testing, and Helen Tsimiklis and Mark Fernando for bio-specimen management, during the 18-year follow-up. 
1 TAHS: The TAHS was initiated by Dr Heather Gibson, Associate Professor Bryan Gandevia, Dr 2 Graham Hall, and Dr Harold Silverstone who was co-opted for his statistical expertise. We thank 3 the project coordinators and the testing and interviewing staff that have conducted the study 4 follow-ups over the study duration, who are too numerous to list here but are gratefully 5 acknowledged.

6 We thank all of the MACS and TAHS participants for their ongoing support for these studies.

\section{REFERENCES}

1. Kuruvilla ME, Lee FE-H, Lee GB. Understanding Asthma Phenotypes, Endotypes, and Mechanisms of Disease. Clin Rev Allergy Immunol. 2019 Apr;56(2):219-33.

2. Australasian Society of Clinical Immunology and Allergy. Laboratory Tests in the Diagnosis of Allergic Diseases [Internet]. Australasian Society of Clinical Immunology and Allergy (ASCIA). [cited 2019 Jul 1]. Available from: https://www.allergy.org.au/hp/papers/tests-in-thediagnosis-of-allergic-diseases

3. Svanes C, Koplin J, Skulstad SM, Johannessen A, Bertelsen RJ, Benediktsdottir B, et al. Father's environment before conception and asthma risk in his children: a multi-generation analysis of the Respiratory Health In Northern Europe study. Int J Epidemiol. 2017 Feb 1;46(1):235-45.

4. Christensen BH, Thulstrup AM, Hougaard KS, Skadhauge LR, Hansen KS, Frydenberg M, et al. Maternal occupational exposure to asthmogens during pregnancy and risk of asthma in 7year-old children: a cohort study. BMJ Open. 2013 Jan 1;3(4):e002401.

5. Lowe AJ, Lodge CJ, Allen KJ, Abramson MJ, Matheson MC, Thomas PS, et al. Cohort Profile: Melbourne Atopy Cohort study (MACS). Int J Epidemiol. 2017 Feb 1;46(1):25-6.

6. Matheson MC, Abramson MJ, Allen K, Benke G, Burgess JA, Dowty JG, et al. Cohort Profile: The Tasmanian Longitudinal Health STUDY (TAHS). Int J Epidemiol. 2017 01;46(2):407-408i. 
1 7. Australasian Society of Clinical Immunology and Allergy. Skin Prick Testing for the Diagnosis of Allergic Disease [Internet]. 2016 [cited 2019 Jul 1]. Available from: https://www.allergy.org.au/hp/papers/skin-prick-testing

8. Braun-Fahrländer C, Wüthrich B, Gassner M, Grize L, Sennhauser FH, Varonier HS, et al. Validation of a rhinitis symptom questionnaire (ISAAC core questions) in a population of Swiss school children visiting the school health services. Pediatr Allergy Immunol. 1997 May $1 ; 8(2): 75-82$.

9. Owens L, Laing |A, Zhang G, Turner S, Le Souëf PN. Prevalence of allergic sensitization, hay fever, eczema, and asthma in a longitudinal birth cohort. J Asthma Allergy. 2018 Aug $13 ; 11: 173-80$.

10. Iversen L, Hannaford PC, Godden DJ, Price DB. Do people self-reporting information about chronic respiratory disease have corroborative evidence in their general practice medical records? A study of intermethod reliability. Prim Care Respir J J Gen Pract Airw Group. 2007 Jun;16(3):162-8.

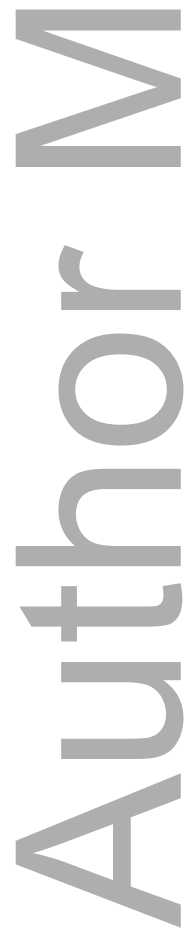

This article is protected by copyright. All rights reserved 


\section{University Library}

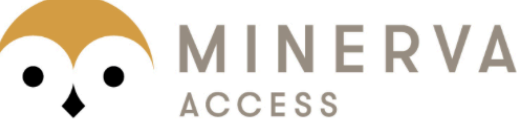

A gateway to Melbourne's research publications

Minerva Access is the Institutional Repository of The University of Melbourne

Author/s:

Pape, K;Schlunssen, V;Lodge, CJ;Perret, JL;Walters, EH;Bui, D;Erbas, B;Svanes,

C;Hamilton, GS;Thomas, PS;Hougaard, KS;Abramson, MJ;Dharmage, SC;Lowe, AJ

Title:

Is self-reported history of eczema and hay fever a valid measure of atopy in those who report current asthma?

Date:

2020-08-07

Citation:

Pape, K., Schlunssen, V., Lodge, C. J., Perret, J. L., Walters, E. H., Bui, D., Erbas, B., Svanes, C., Hamilton, G. S., Thomas, P. S., Hougaard, K. S., Abramson, M. J., Dharmage, S. C. \& Lowe, A. J. (2020). Is self-reported history of eczema and hay fever a valid measure of atopy in those who report current asthma?. ALLERGY, 75 (11), pp.2981-2985. https:// doi.org/10.1111/all.14440.

Persistent Link:

http://hdl.handle.net/11343/276121 